\title{
Comparison between Neutron Diffraction Measurements and Numerical Simulation of Residual Stresses of a Wire-drawing Process
}

\author{
Tomaz Fantin de Souza ${ }^{\text {a*, Carla Adriana Theis Soares }}{ }^{\mathrm{a}}$, Juliana Zottis ${ }^{\mathrm{a}}$, \\ Rafael Menezes Nunes ${ }^{\mathrm{a}}$, Alexandre da Silva Rocha ${ }^{\mathrm{a}}$, Thomas Hirsch ${ }^{\mathrm{b}}$ \\ ${ }^{a}$ Laboratório de Transformação Mecânica - LdTM, Centro de Tecnologia - CT, \\ Universidade Federal do Rio Grande do Sul-UFRGS, Av. Bento Gonçalves, 9500, \\ Bairro Agronomia, Porto Alegre, RS, Brasil \\ ${ }^{\mathrm{b} S t i f t u n g}$ Institut für Werkstofftechnik, Universität Bremen, Badgasteiner Str. 328359 Bremen
}

Received: August 8, 2012; Revised: October 16, 2012

\begin{abstract}
In this work, a drawing processed was simulated to calculate forces and the resulting residual stresses in the material. The calculated residual stresses were compared with experimentally measured residual stresses by the Neutron Diffraction Method. The modeled process was the Wire Drawing. The necessary parameters to model the process were taken from an industrial currently used process. Rods of an AISI 1045 steel with nominal diameters of $21.46 \mathrm{~mm}$ were reduced to $20.25 \mathrm{~mm}$ by drawing with an drawing angle of $15^{\circ}$. Compression tests were used to determinate flow curves of the real material an used in the simulation models. The possibility to estimate drawing forces by numerical simulation was evaluated by comparing simulated results with values from empirical equations given by the literature. The results have shown a sufficient accuracy for the calculation of forces, but the comparison of residual stresses has shown differences to the experimentally determined ones that can be minimized by the consideration of high strain rates in the compression tests, anisotropy of the material and kinematic hardening.
\end{abstract}

Keywords: cold drawing, residual stresses, numerical simulation

\section{Introduction}

The use of drawn products has increased in the last years ${ }^{1}$. Drawn bars with different diameters are used in the manufacturing of automotive parts, reducing subsequent machining steps, costs and energy consumption. The wire drawing can be defined as a manufacturing process by plastic deformation in which the raw material (wire rod) is pulled through a die, thus causing a reduction in cross sectional area and an increase in the length. Some of the main features of the wire drawing process are the achievement of an excellent surface finishing and good dimensional accuracies, increase in mechanical strength and high processing speeds ${ }^{2}$. The main raw material used in the drawing of bars is the wire rod, i.e., rolled steel of continuous section, usually cylindrical, supplied as coils.

When a material is processed by plastic deformation, as in the case of wire drawing, residual stresses arise, which can affect mechanical properties and the behavior of the material in distortion (dimensional and shape changes after heat treatment), sometimes they can lead to catastrophic failure of a component in service. Residual stresses also interfere in later steps of the manufacturing route of a particular component, due to a redistribution of these stresses that occurs as a result of mechanical and thermal loads and metallurgical transformations, at each manufacturing step.

*e-mail: tomazfs@yahoo.com.br
Since the 60's of the last century, the application of numerical analysis using, among others, the finite element method $^{3}$, has allowed to improve the study of different manufacturing processes. Simulation avoids design errors that may involve high costs in its correction by long stages of "try-out". Thus, finite element computer simulation improves the process before construction of prototypes, avoiding unnecessary investments ${ }^{4}$. In the case of wire drawing, it can improve the workpiece dimensions, die's geometry and final material's properties by optimizing process parameters, among other possibilities. An inappropriate value of the parameters such die angle and friction coefficient can increase the level of the residual stresses in the final product ${ }^{5,6}$. The main objective of this work is the evaluation of the residual stresses generated in a wire drawing process by simulation and experimental measurements.

The simulations were carried out using finite elements and considering an AISI 1045 isotropic steel. The experimental measurements were carried out by Neutrons Diffraction. In this work the results of residual stresses of both methods were compared, simulation and experimental. These results are important in further steps to understand the contribution of the residual stresses as a potential of distortion. 


\section{Material and Methods}

An industrial process of wire drawing of round bars of AISI 1045 steel with a diameter reduction from $21.46 \mathrm{~mm}$ to $20.25 \mathrm{~mm}$ was simulated for only one drawing angle $15^{\circ}$. The material used was an AISI 1045 rolled steel with a chemical composition shown in Table $1^{[7]}$.

A finite element simulation with a 2D and 3D model was carried out to reproduce a drawing process and investigate failures to optimize the process. The $3 \mathrm{D}$ model was chosen to compare results. Results of simulated force and empirical equations were compared. The simulated residual stresses were compared with experimentally obtained values by means of the Neutron Diffraction Method.

\subsection{Measurement of residual stresses in cold drawn bars by neutron diffraction}

The neutron diffraction residual stress measurements were performed at the Helmholtz Zentrum Berlin, in Berlin, Germany; on beam line E3 of the BER II reactor.

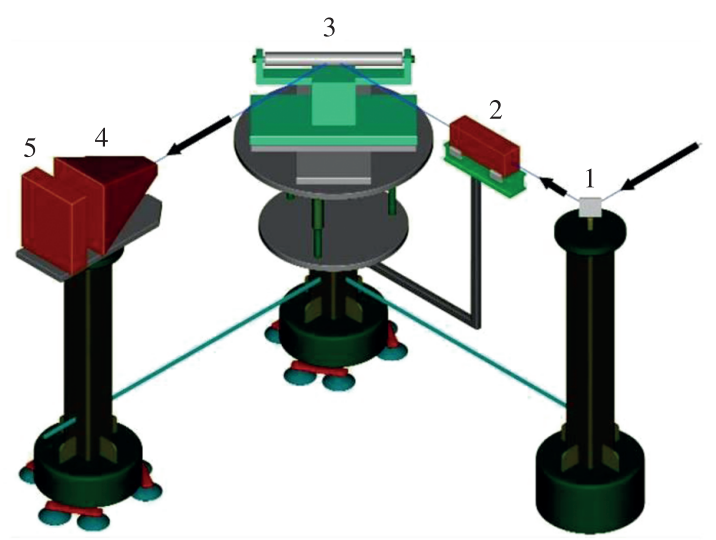

Figure 1. Schematic sketch of the instrument where (1) monochromator, (2) incident beam aperture, (3) sample, (4) diffracted beam mask, (5) detector.
The primary beam path is composed by a segmented elastically bent Silicon monochromator giving a high neutron flux. The diffracted beam is recorded with a $3 \mathrm{He}$ Position Sensitive Detector of $300 \mathrm{~mm} \times 300 \mathrm{~mm}$ of size using $256 \times 256$ channels. A diffractometer with automatic xyz translation table was used. The distance between the diffractometer centre and the detector was $1.3 \mathrm{~m}$. Details about the equipment of the beam line can be found in Poeste et al. ${ }^{8}$. The method is a non-destructive test, that does not require cutting or electrolytic polishing to obtain the profiles of residual stresses, taking into account that neutron have a high penetration in the range of tenths of a millimeter.

A schematic sketch is presented in Figure 1, sketches of the samples in the three measurement directions are given in Figure 2. At the primary side, a mask with a square cross section of $2 \times 2 \mathrm{~mm}$ was used. The aperture at the secondary side was accordingly $2 \mathrm{~mm}$ in width with no height limitations. As the neutron beam has almost no divergence, the use of a mask at the primary side and an aperture in the diffracted beam allows selecting the diffracting volume quite precisely. The scattering vector is perpendicular to the measured $\{h k 1\}$ planes. Exclusively the $\{211\}$ diffraction line of $\alpha$-iron was selected for the measurements. The wavelength for the experiments was $0.1486 \mathrm{~nm}$, so that the peak position was around $78.8^{\circ}$ in $2 \theta$. As it can be seen from Figure 2, the volume elements in the diffractometer plane have the shape of rhombuses due to the $2 \theta$ angle of $78.8^{\circ}$ related to monochromator wavelength, material and chosen lattice plane. The measurements were executed mainly in the central plane of the bars at $100 \mathrm{~mm}$ distance from one end along a radius line of the bar. The coordinate system of the measurements was placed at the central plane and in the center line of the sample. Accordingly, volume elements were placed at positions $-10 \mathrm{~mm},-9 \mathrm{~mm},-8 \mathrm{~mm}$, etc. up to $+8 \mathrm{~mm},+9 \mathrm{~mm}$ and $+10 \mathrm{~mm}$ and in summary 20 measurements were executed. The zero position of the bars as marked from the manufacturing process was always set to the position $+10 \mathrm{~mm}$. From Figure 2 it should be also

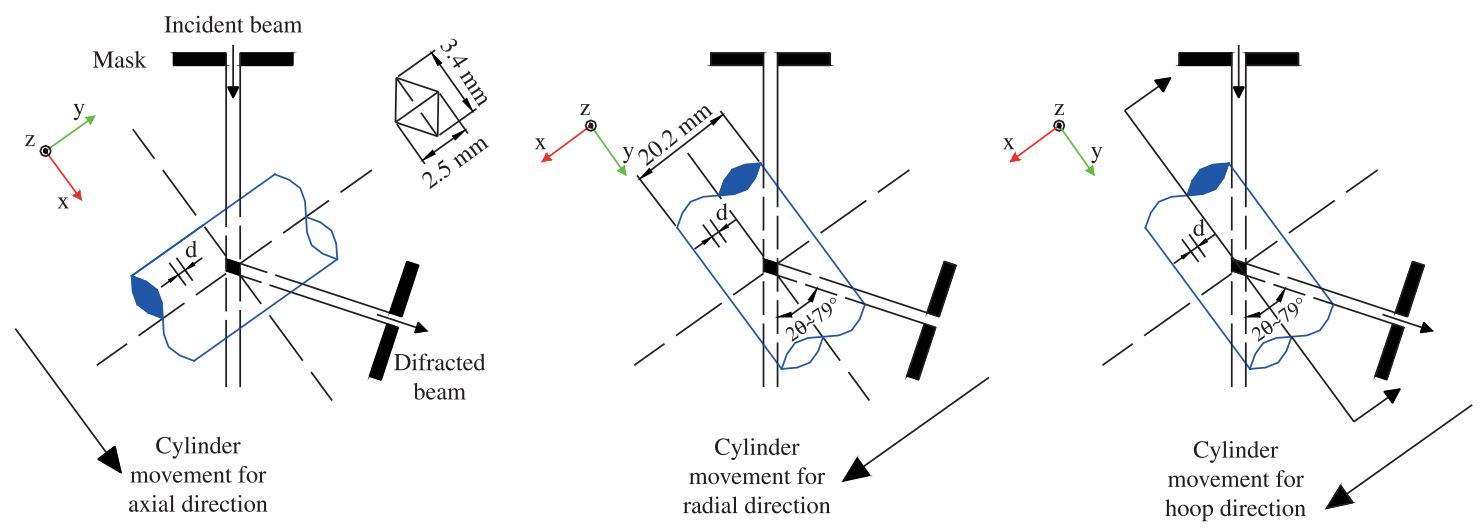

Figure 2. Conditions for the measurement of the three residual strain components in one sample.

Table 1. Chemical composition of used steel.

\begin{tabular}{ccccccccccc}
\hline Alloying element & $\mathbf{C}$ & $\mathbf{S i}$ & $\mathbf{M n}$ & $\mathbf{P}$ & $\mathbf{S}$ & $\mathbf{C r}$ & $\mathbf{M o}$ & $\mathbf{N i}$ & $\mathbf{C u}$ & $\mathbf{N b}$ \\
\hline$\%$ mass & 0.43 & 0.24 & 0.79 & 0.03 & 0.02 & 0.13 & 0.03 & 0.08 & 0.1 & $<0.01$ \\
\hline
\end{tabular}


noticed that gauge volumes at $10 \mathrm{~mm}$ and $9 \mathrm{~mm}$ positions also covered laboratory air and deviations of line positions could be expected with the use of plane apertures. The set-up of the instrument however was used to minimize these effects. For the analysis of the diffraction pattern, the Software Stresstex developed by C. Randau of FRMII/TUM has been used. The two-dimensional diffraction frames are integrated and the obtained diffraction peaks are fitted by a Gaussian after back-ground subtraction. The strain is calculated with Equation 1 from the position of the diffraction line corresponding to the $\{h k l\}$ plane of the measured phase, giving a lattice spacing $d\{h k l\}$ through the Bragg's law (Equation 2), and the stress free lattice spacing $\mathrm{d}_{0}$. Residual stresses in the considered directions are calculated by Equation 3, where $1 / 2 \mathrm{~s}_{2}\{\mathrm{hkl}\}=(1+v\{\mathrm{hkl}\}) /$ $\mathrm{E}\{\mathrm{hkl}\}$ and $\mathrm{s}_{1}\{\mathrm{hkl}\}=-\mathrm{v}\{\mathrm{hkl}\} / \mathrm{E}\{\mathrm{hkl}\}$ and $\varepsilon\{\mathrm{hkl}\}$ is the strain measured in directions $\mathrm{x}, \mathrm{y}$ and $\mathrm{z}$.

$\varepsilon_{i}^{\{h k l\}}=\frac{d_{i}^{\{h k l\}}-d_{0}^{\{h k l\}}}{d_{0}^{\{h k l\}}}$

$n \bullet \lambda=2 \bullet d_{\{h k l\}} \bullet \sin \Theta$

$\sigma_{x}=\frac{1}{1 / 2 s_{2}^{\{h k l\}}}\left[\varepsilon_{x}^{\{h k l\}}-\frac{s_{1}^{\{h k l\}}}{1 / 2 s_{2}^{\{h k l\}}+3 s_{1}^{\{h k l\}}}\left(\varepsilon_{x}^{\{h k l\}}+\varepsilon_{y}^{\{h k l\}}+\varepsilon_{z}^{\{h k l\}}\right)\right]$

The balance of residual stresses was checked out as a way to adjust the measured values, since in neutron diffraction the measurement accuracy depends on the determination of the interplanar distance without the action of residual stresses, i.e., the $d_{0}$ value .

In the analysis, the interplanar distances of the $\{211\}$ plane of the $\alpha$-iron were measured for axial, radial and hoop directions for a single volume element in the sample of approximately $1 \mathrm{~mm}^{3}(1 \mathrm{~mm} \times 1 \mathrm{~mm} \times 1 \mathrm{~mm})$. From the interplanar distances, the principal strains were calculated, using the specific elastic constants to obtain the values of the principal normal residual stresses (for axial, hoop and radial directions). The specimens of drawn bars had $200 \mathrm{~mm}$ in length and $20.25 \mathrm{~mm}$ in diameter. The measurements were carried out after drawing, measuring across the middle plane of the specimens, from the $0^{\circ}$ position to the $180^{\circ}$ position, with approximately $1 \mathrm{~mm}$ step size. To clarify, $0^{\circ}$ is the up-side line and $180^{\circ}$ was the down-side line taking as a reference the position of the bar as it passes the drawing tool. Therefore, a complete cross section profile of the residual stresses was obtained for each measured specimen.

\subsection{Numerical simulation of drawing process}

A numerical model was generated in the Simufact. forming GP® software to study the state of residual stresses generated by the drawing of an AISI 1045 hot rolled steel. First, a two-dimensional axisymmetric model was used, allowing to reduce the calculation time. In addition, a three-dimensional model was developed to check if would appear any differences in the results obtained using this model compared to the axisymmetric model.
In order to apply the finite element method [FEM], the solid must have its geometry subdivided into several parts, which are finite elements. This subdivision is done through a mesh, usually consisting of a two-dimensional case, triangles or quadrilaterals whose vertices are the nodes of the mesh. A system of equations is mounted through the nodes whose solution determines the magnitudes of interest in the phenomenon used ${ }^{10,11}$. In this work, a quadrilateral mesh (Quad) for two-dimensional simulation and a hexahedral mesh (Hex) for 3D simulation were used, in the both cases, the used elements have $1 \mathrm{~mm}$ in width and $1 \mathrm{~mm}$ in length.

The Coulomb friction coefficient $(\mu)$ used in the simulation of drawing was 0.1 . This value was obtained by ring compression tests and a comparison with calibration curves obtained by simulation. The details of this comparison can be seen in Rocha et al. ${ }^{12}$.

The simulation process was carried out considering the non-linear elastic-plastic model of plasticity using the flow curve for the material under investigation. The tool was considered rigid, the remeshing criterion was not taken into account and coupled mechanical-thermal effects were not considered in the simulation.

To calculate the stress by numerical simulation, the nonlinear characteristics of the material, the rule of hardening and the plastic strain under loading were given by the von Misses Criterion for the isotropic model and the Hill Criterion for the anisotropic model.

The used isotropic flow curve was taken from compression tests carried out for the AISI 1045 material detailed in Soares ${ }^{13}$, that didn't take into account the high strain rates as the data bank of the simulation software ${ }^{12}$. The strain rates of this process arrive to $40 \mathrm{~s}^{-1}$. The obtained flow curve is given by Equation 4.

$k_{f}=1292.8 . \varphi^{0.2018}$

In equation, $\mathrm{k}_{\mathrm{f}}$ is the flow stress and $\phi$ is the true strain $\left(\phi=\ln \left(A_{0} / A_{1}\right)\right), A_{o}$ and $A_{1}$ are the initial and final area of the bar.

The other parameters used in the numerical simulation are shown in Table 2. The drawing speed of $1250 \mathrm{~mm} / \mathrm{s}$ was estimated from real industrial applications.

To apply the drawing speed (V) a device called "puller" attached to the end of the bar was used, which simulates the effect of the mechanical device that pulls the workpiece during the real process of wire drawing. The model is shown in Figure 3.

The modelled bar (as shown in Figure 3) has $200 \mathrm{~mm}$ in length and $21.46 \mathrm{~mm}$ in diameter, and the die has a total length of $30 \mathrm{~mm}$, which is divided into four regions:

- Entry region (1): it has $5 \mathrm{~mm}$ of length. The angle in this region is slighter bigger than the drawing angle. It serves to guide the material to be drawn and facilitate lubrication;

- Work region (2): it has $15 \mathrm{~mm}$ in length and it is characterized by the drawing angle $(2 \alpha)$, which is the most important parameter of the process. It impacts directly on the drawing force. In this region the main plastic transformation of the material is carried out. 
- Calibration Region (3): It has $5 \mathrm{~mm}$ of length. In this region there is no inclination. This region is important to stabilize the material properties by homogenizing the plastic strains;

- Output region (4): it has an opposite angle in relation to the entry angle. It allows the elastic return of the material when it leaves the die, minimizing the material-tool friction and guiding the material to the out side of the tool.

In the carried out simulation, the state of residual stresses was calculated at the end of the process, after the bar have crossed all the die and therefore had no more external loads applied to it. Also the analysed cross section of the bar was taken at midle length with a sufficient distance from the bar ends, such that no influence from the ends could be seen.

\section{Results and Discussion}

The ability of numerical simulation to predict the drawing force was verified by comparison of numerical results with the equations of Siebel ${ }^{2}$ given in Equation 5, and of Sachs ${ }^{14,15}$ given in Equation 6.

Table 2. Parameters of the wire drawing simulation.

\begin{tabular}{cc}
\hline Analysis & $\begin{array}{c}\text { 2D and 3D } \\
\text { mechanical }\end{array}$ \\
\hline Elements & $2000(2 \mathrm{D}) / 52000$ \\
Element type & Quad (2D)/Hex \\
Material & $(3 \mathrm{D})$ \\
Coulomb friction coefficient $(\mu)$ & AISI 1045 \\
Initial and final diameter & 0.1 \\
Initial temperature & 21.46 and $20.25 \mathrm{~mm}$ \\
Drawing angle $(2 \alpha)$ & $20^{\circ} \mathrm{C}$ \\
Young modulus & $15^{\circ}$ \\
Poisson coefficient & $210 \mathrm{GPa}$ \\
& 0.3 \\
\hline
\end{tabular}

$$
\begin{aligned}
& F=A_{1} \cdot K_{f m} \cdot \varphi_{A}\left(1+\frac{\mu}{\alpha}+\frac{2}{3} \cdot \frac{\alpha}{\varphi_{A}}\right) \\
& F=A_{1} \cdot k_{f m} \cdot\left(1+\frac{1}{\mu \cdot \cot \alpha}\right) \cdot\left[1-\left(\frac{A_{1}}{A_{0}}\right)^{\mu \cdot \cot (\alpha)}\right]
\end{aligned}
$$

In Equations 5 and 6, $\mathrm{A}_{0}$ and $\mathrm{A}_{1}$ are the cross section areas of the bar, respectively before and after wire drawing in square millimeters $\left(\mathrm{mm}^{2}\right), \mathrm{k}_{\mathrm{fm}}$ is the mean yield stress in Mega-Pascal (MPa), $\mathrm{j}_{\mathrm{A}}$ is the true equivalent strain which is equal to the "area true strain" given by Neperian logarithm of the initial area by the final area, $\mu$ is the Coulomb friction coefficient and $\mathrm{a}$ is half of the drawing angle, as indicated in Figure 3.

Table 3 presents the results of simulated and calculated forces. The maximum difference between the calculated and simulated forces for the drawing angle of $15^{\circ}$ is $26 \%$ for the $3 \mathrm{D}$ simulation, and $14 \%$ for 2D simulation. Differences between the simulation and the theoretical equations were found and can be originated from several factors, including the limitations in the equations, for example, they do not take into account the calibration region that would change the result of forces, reducing the difference.

The 3D model has 52000 elements and the 2D model has 2000 elements, this means a more detailed calculation for the 3D model. Another explanation is that the used meshes are different in 3D and 2D models, for the 3D model a hexahedral mesh (Hex) has to be used while for 2D model the quadrilateral mesh (Quad) was applied.

The simulated values of residual stresses, Figure 4, were compared with experimental values obtained by the Neutron Diffraction method. In this figure, the comparison of residual stress profiles across the middle length of drawn bars is presented for drawing angles of $15^{\circ}$.

The results of residual stresses are presented in Figure 4.

Figure 4 shows the profiles of residual stresses for the $15^{\circ}$ drawing angle. Where in Figure 4 a the numerical model of residual stresses is shown for the axial direction after drawing; and in Figure 4b profiles of residual stresses for

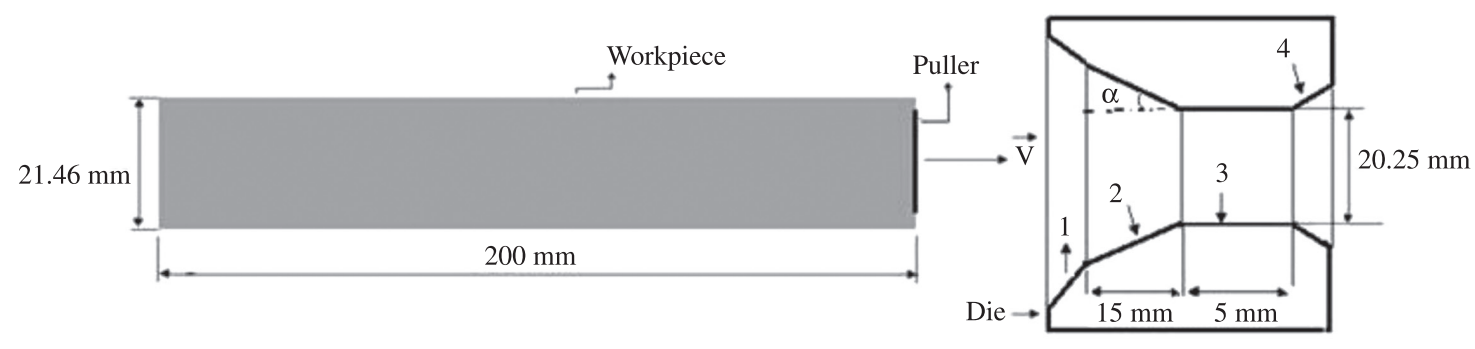

Figure 3. Model created for 3D and 2D simulation.

Table 3. Comparison between the simulated and calculated results of force.

\begin{tabular}{ccccc}
\hline Type of simulation & Drawing angles & Simulated force $(\mathbf{N})$ & Siebel force $(\mathbf{N})$ & Sachs force $(\mathbf{N})$ \\
\hline 2D Simulation & $15^{\circ}$ & 71170 & 64361 & 65292 \\
3D Simulation & $15^{\circ}$ & 86638 & 64361 & 65292 \\
\hline
\end{tabular}




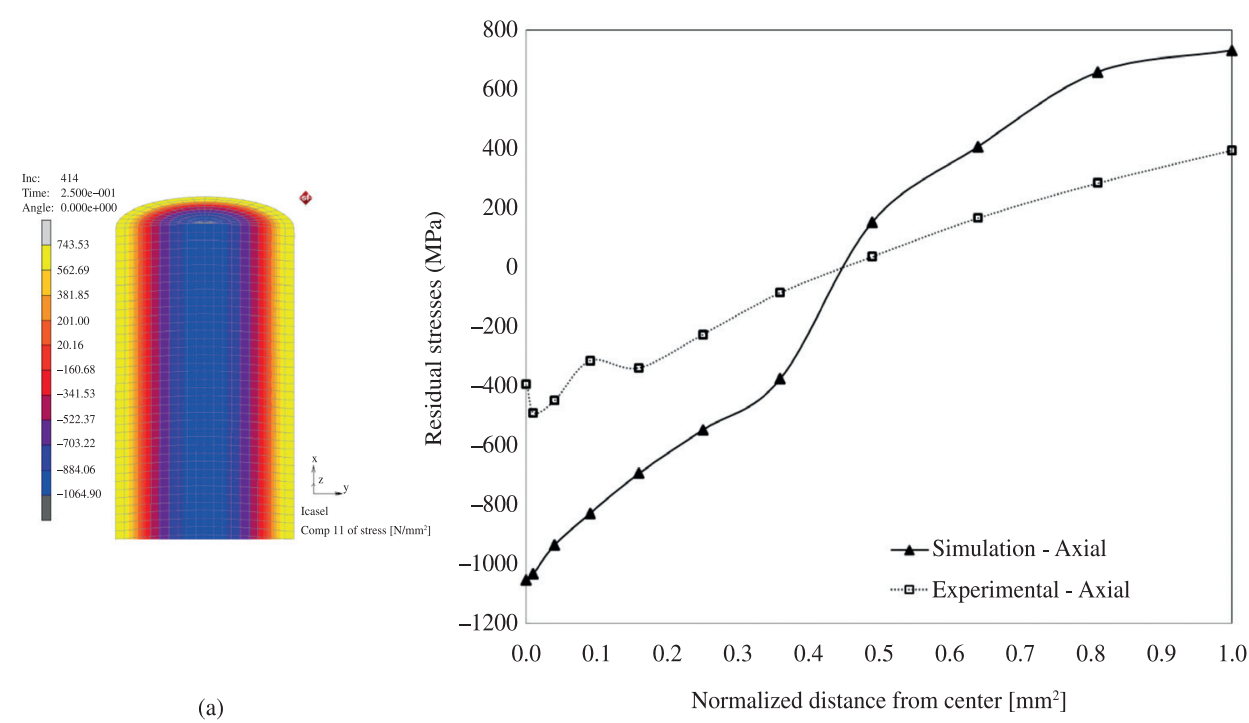

(a)

(b)

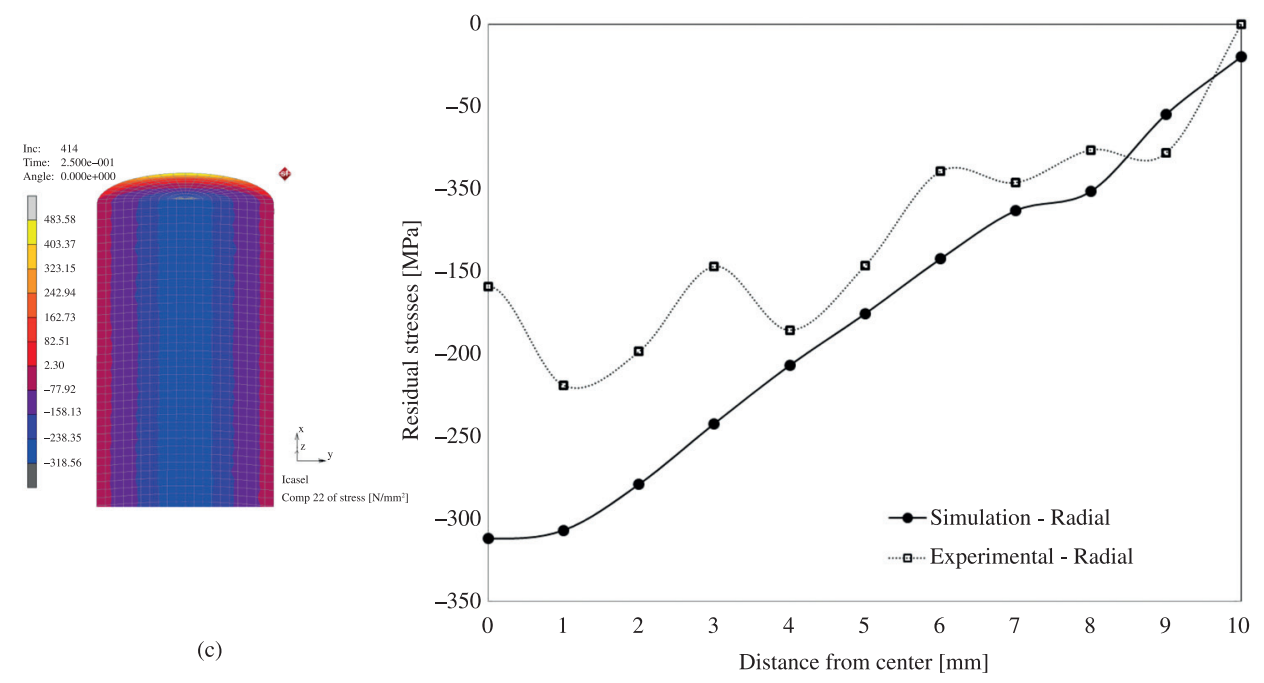

(d)

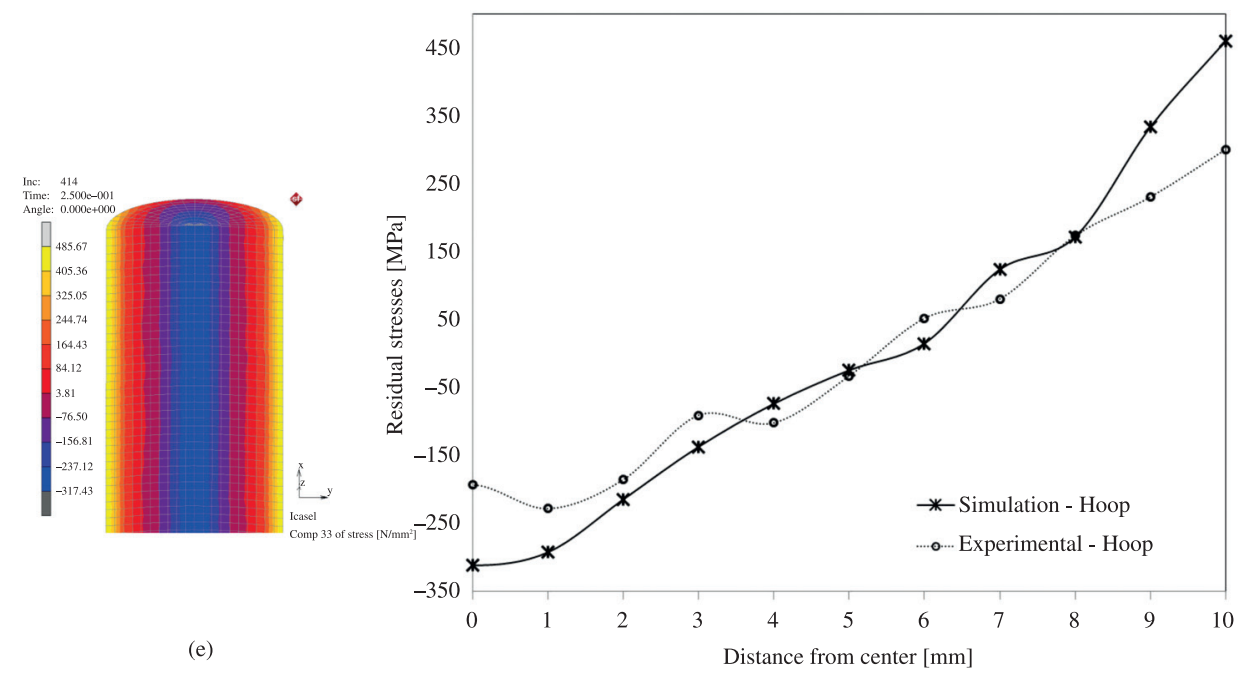

(f)

Figure 4. Profile of residual stresses for die angle $15^{\circ}$ (a) and (b) axial direction, (c) and (d) radial and (e) and (f) hoop directions. 
the axial direction as function of the cross-sectional area are shown, where the points -1 and 1 represent the surfaces of the bar and the point 0 represents the center of the bar.

Figure $4 \mathrm{c}$, e show the residual streses in the simulated bar for radial and hoop directions, respectively. The Figure 4d, f show the results of residual stresses for the radial and hoop directions, where the points -10 and 10 represent the surface and the point 0 is the center of the bar.

The profile of axial residual stresses shows a tensile value at surface and compressive at the center of the bar. For the $15^{\circ}$ drawing angle (Figure $4 \mathrm{~b}$ ) the profile of simulated axial residual stresses has a maximum value of $730 \mathrm{MPa}$ at the surface, and a minimum at the center of the bar of $-1055 \mathrm{MPa}$. By comparing simulation and experiment, it can be seen for both drawing angles that the simulation gave higher values for the surface and lower values for the center, as a consequence of the stresses balance. In the Figure $4 b$, a maximum difference of around $337 \mathrm{MPa}$ at the surface and $-659 \mathrm{MPa}$ for the center of the bar is seen.

Figure $4 d$ shows now the results for radial direction, a compressive behavior of the residual stresses is observed throughout the cross section of the bar for the radial direction, and the hoop residual stresses has a similar behaviour as for the axial direction. Also the radial component is approaching zero close to the surface, as also it should be, the radial component will be a normal to the surface at surface, therefore should tend to the zero. The differences in the residual stresses between simulation and experiment are $-153 \mathrm{MPa}$ in the center of the bar.

As reported in the literature ${ }^{16-18}$ the values of axial and hoop residual stresses after wire drawing should be close to each other for positions close to the surface, which agrees with the simulated results. Also the most important component of residual stresses for the material behavior and highest one is in the axial direction, as it causes bending after heat treatment and can lead to longitudinal cracking.

The comparison of simulation with the experimental, Figure 4f, results shows differences for the hoop direction with a maximum of $160 \mathrm{MPa}$ for the surface and $-118 \mathrm{MPa}$ for the center of the bar. Both simulation and the experimental results show also equal values of hoop and radial in the center.

There are different reasons for the observed differences between experiment and simulation. First of all, at the proposed model, the material is considered isotropic, when in reality, the behavior is anisotropic, because the bars are initially manufactured by a rolling process that inserts anisotropy due to grains elongation in the rolling direction. The used flow curves are normally obtained for the axial direction and it can be expected a decrease of the yield stress for the transverse (or radial) direction. Since residual stresses are limited by the yield stresses, this consideration would decrease the simulated residual stresses in the surface and increase them in the center, i.e., turn the profiles generally more flat as measured by neutrons. According to the literature ${ }^{16,17}$, the consideration of an isotropic material, led to an overestimation of residual stresses in the order of $200 \mathrm{MPa}$ at the center of the bar to the axial direction. It is therefore very important to consider the effects of anisotropy of the material in the continuation of these studies.

Another possible effect, is the kinematic hardening, which also occurs in the material due to deformation caused in steps previous to drawing, that generates deformation in more than one direction ${ }^{19}$, which occurs during the wire drawing and probably generates the Baushinger effects. Also, in the compression tests to obtain the flow curves did not be consider high strain rates were not considered which would result in elevation of the curve and resulting modification of the residual stresses. In addition, the real bars have residual stresses before drawing due to previous processing steps, which can superimpose the residual stresses generated during drawing, and in the present study bars were initially considered as stress-free bodies. This could be minimized applying appropriate boundary conditions that would reflect the initial state of the material, as for example, simulating the previous steps and taking the obtained state of stresses as initial state for the simulation of the wire drawing process.

\section{Conclusion}

Analyzing the calculated and simulated forces, the differences are close to $26 \%$ for the die angle of $15^{\circ}$ in the case of 3D simulation and differences around $10 \%$ in the case of $2 \mathrm{D}$ simulation. These simulation results are satisfactory if the aim is to evaluate necessary drawing forces.

For the analysis of residual stresses, the profile of simulated results showed similar trends as the experimental ones, with the same influences of drawing angle, but the quantitative values were not satisfactory when compared with the experimental values. This is attributed to the fact that in the simulation the anisotropy of the bar was not taken into account, and besides that probably there were effects of previous stages of processing and kinematic hardening, whose influences must be further investigated.

\section{Acknowledgements}

The authors are deeply in debt to CNPq, CAPES and FINEP for financial support in the frame of the BRAGECRIM program (Brazilian German Collaborative Research Initiative in Manufacturing Technology) for the finance of the research and to the Helmholtz Zentrum Berlin where the experimental analysis of residual stresses by Neutron Diffraction have been carried out. 


\section{References}

1. Lange K. Handbook of Metal Forming. Society of Manufacturing Engineers; 2006. p. 13-24.

2. Dieter GE. Metalurgia Mecânica. Rio de Janeiro: Guanabara Dois; 1981. p. 653.

3. Woo DM. On the complete solution of the deep-drawing problem. International Journal of Mechanical Sciences. 1968; 10:83-94. http://dx.doi.org/10.1016/0020-7403(68)90065-9

4. Tekkaya AE. State-of-the-art of Simulation of Sheet Metal Forming. Jornal of Materials Processing Technology. 2000; 103:14-22. http://dx.doi.org/10.1016/S0924-0136(00)00413-1

5. Nunes RM. Análise de Tensões Residuais de Aços Aisi 1048 Produzidos por Trefilação Combinada Visando Minimizar Distorções Pré-Processamento. [Dissertação]. Porto Alegre: Universidade Federal do Rio Grande do Sul; 2008.

6. Rocha AS, Nunes RM and Hirsch T. Changes in the axial residual stresses in AISI 1045 steel bars resulting from a combined drawing process chain. Proceedings of the Institution of Mechanical Engineers. Part B. Journal of Engineering Manufacture. 2011B; 226:459-465. http://dx.doi. org/10.1177/0954405411422299

7. Rocha AS, Nunes RM and Hirsch T. Analysis by design of experiments of distortion potentials in drawn and induction hardened wire. Materials Research. 2012; 15:266-276. http:// dx.doi.org/10.1590/S1516-14392012005000020

8. Poeste T, Wimpory RC and Schneider R. The new and upgraded neutron instruments for material science at HMI - current activities in cooperation with industry. Materials Science Forum. 2006; 524-525:223-228. http://dx.doi.org/10.4028/ www.scientific.net/MSF.524-525.223

9. Hauk V. Structural and Residual Stresses Analysis by NonDestructive Methods. Elsevier; 1997. p. 530.

10. Gambin W. A Method of Large Finite Elements. Computer Methods in Applied Mechanics and Engineering. 1977; 351-65.
11. Norasethasopon S and Yoshida K. Prediction of Chevron Crack Initiation in Inclusion Copper Shaped-Wire Drawing. Engineering Failure Analysis. 2008; 15:378-93. http://dx.doi. org/10.1016/j.engfailanal.2007.01.003

12. Rocha AS, Haenisch S, Coser TB, Souza TF and Soares CAT. Simulação computacional de um processo de trefilação para produção de barras redondas de aço AISI 1045. Revista Escola de Minas. 2011A; 64:513-518. http://dx.doi.org/10.1590/ S0370-44672011000500018

13. Soares CAT. Análise das Tensões Residuais no Processo de Trefilação Considerando os Efeitos de Anisotropia. [Dissertação]. Porto Alegre: Universidade Federal do Rio Grande do Sul; 2012.

14. Gerbase Filho J. Método de Medição de Força de Trefilação de Arames: Avaliação da Variação do Coeficiente de Atrito em Trefilação de Arames de Aço. [Dissertação]. Porto Alegre: Universidade Federal do Rio Grande do Sul; 1976.

15. Schaeffer L. Conformação Mecânica. 2. ed. Porto Alegre: Imprensa Livre Editora; 2004.

16. Atienza JM, Ruiz-Hervias J, Martinez-Perez ML, Mompean FJ, Garcia-Hernandez M and Elices M. Residual Stresses in Colddrawn Pearlitic Rods. Scripta Materialia. 2005A; 52(12):12231228. http://dx.doi.org/10.1016/j.scriptamat.2005.03.003

17. Atienza JM, Martinez-Perez ML, Ruiz-Hervias J, Mompean F, Garcia-Hernandez M, Elices M. Residual Stresses in Colddrawn Ferritic Rods. Scripta Materialia. 2005B; 52(4):305309. http://dx.doi.org/10.1016/j.scriptamat.2004.10.010

18. Martinez-Perez ML, Mompean FJ, Ruiz-Hervias J, Borlado CR, Atienza JM, Garcia-Hernandez M et al. Residual Stresses Profiling in the Ferrite and Cementite Phases of Cold-drawn Steel Rods by Synchrotron X-Ray and Neutron Diffraction. Acta Materialia. 2004; 52(18):5303-5313. http://dx.doi. org/10.1016/j.actamat.2004.07.036

19. Ottosen NS. Nonlinear Kinematic Hardening under NonProportional Loading. Copenhagem: Riso National Laboratory; 1979. 